Www.jmscr.igmpublication.org

Impact Factor (SJIF): 6.379

Index Copernicus Value: 79.54

ISSN (e)-2347-176x ISSN (p) 2455-0450

crossrefDOI: https://dx.doi.org/10.18535/jmscr/v6i11.10

Journal Of Medical Science And Clinical Research

\title{
A Prospective study on outcome following mechanical ventilation among children in a tertiary care hospital
}

Authors

\section{Dr D.Sankari ${ }^{1}$, Dr C.S. Balachandran ${ }^{2}$, Dr S. Chidambaranathan ${ }^{3}$}

${ }^{1}$ Post Graduate, Department of Pediatrics, Rajah Muthiah Medical College, Chidambaram

${ }^{2}$ Professor, Department of Pediatrics, Rajah Muthiah Medical College, Chidambaram

${ }^{3}$ Reader, Department of Pediatrics, Rajah Muthiah Medical College, Chidambaram

\begin{abstract}
Background: Mechanical ventilation $(M V)$ in paediatric intensive care unit is a major therapeutic modality especially among children with respiratory distress and apnoea. Adequate sedation, frequent vitals monitoring, urine output are essential in titrating the ventilator settings to act in harmonious for the babies.

Methods: In total, thirty one children of age less than twelve years and greater than a year of age requiring $M V$ comprised the study group. Pressure controlled ventilation was done initially among all the patients. Then the children were weaned to synchronized intermittent mechanical ventilation, continuous positive airway pressure and extubation done following trial of T-piece.

Results: The mean duration of mechanical ventilation was $3.65 \pm 1.64$ with range from seven to one day/s.Two patients were expired on the first day of mechanical ventilation due refractory disseminated intravascular coagulation following drowning $(n=3)$.

Discussion: Ventilator associated pneumonia, multiple organ failure, septic shock, cardiovascular insufficiency and gastrointestinal bleeding occurs frequently following $M V$. The frequency of these complications is lower among children under low volume and pressure settings.

Conclusion: The point prevalence of ventilator associated pneumonia was 19.35 seen in bronchiolitis $(n=4)$ and refractory seizure $(n=2)$. Relatively poor outcome is seen among children under $M V$ when done for apnoea and hypoxemia.
\end{abstract}

\section{Introduction}

Mechanical ventilation (MV) in paediatric intensive care unit is a major therapeutic modality especially among children with respiratory distress and apnoea. In the emergency department, the overall rate of securing the airway by first pass intubation is $60 \%$ among children and $50 \%$ in babies not more than two years. Though the favourable outcome is low, the airway securing rate is high when done by rapid sequence intubation protocol ${ }^{(1)}$. Overzealous incoherent mode of ventilator settings for children may increase the rate of ventilator related lung injury. Proper aseptic protocol necessitates no need of higher antibiotic throughout the course of therapy $^{(2) .}$ The incidence of pneumonia following mechanical ventilation is $22.9 \%$ among critical ill children in Iranian children ${ }^{(3)}$. Half yearly survival following haematopoietic stem cell transplantation in children with respiratory failure was $25 \%$. 
Heart failure has increased the odds of fatality in MV children when compared to Multi-organ failure. However, patients on large volume inotrope infusions, MV not less than seven days or with continuous renal replacement therapy also aggravates the risk of fatality ${ }^{(4)}$. Optimal machine patient interaction is essential for diffusion of gases in the alveoli and perfusion into the bloodstream. Adequate sedation, frequent vitals monitoring, urine output are essential in titrating the ventilator settings to act in harmonious for the babies $^{(5)}$.

\section{Methods}

The study was conducted prospectively in Paediatric Intensive care unit, Department of Paediatrics, Rajah Muthiah Medical College and Hospital, Chidambaram from September 2017 to October 2018. In total, thirty one children of age less than twelve years and greater than a year of age requiring MV comprised the study group. Those requiring concurrent renal replacement therapy, babies with multi-organ failure and nil paternal consent were excluded from the study.Demographic details, indication for intubation, duration of MV and each mode, reintubation after extubation was noted. Data were stored confidentially under regular supervision. Pressure controlled ventilation was done initially among all the patients. Then the children were weaned to synchronized intermittent mechanical ventilation, continuous positive airway pressure and extubation done following trial of T-piece. Midazolam and fentanyl was used for sedation. Children were followed throughout the entire course of stay under intensive care. Specific treatment for the diagnoses was given as per the protocol followed in the hospital. Data was analysed by descriptive statistics function in the Microsoft Excel 2010.

\section{Results}

The mean duration of mechanical ventilation was $3.65 \pm 1.64$ with range from seven to one day/s. Two patients were expired on the first day of mechanical ventilation due refractory disseminated intravascular coagulation following drowning $(n=3)$. Refractory seizures $(n=6)$, meningitis $(\mathrm{n}=2)$ and anaplastic ependymoma with hydrocephalus ( $\mathrm{n}=1$; expired) comprises the CNS diseases. Bronchiolitis $(\mathrm{n}=6)$ and Lower respiratory tract infection $(n=2$; expired) were the respiratory diseases encountered. Hypertropic obstructive cardiomyopathy $(\mathrm{n}=1)$ and dilated cardiomyopathy $(n=1$; expired) were the cardiac condition requiring MV. Scorpion $(n=5)$, snake envenomation ( $\mathrm{n}=1$; expired) and organophosphorous compound poisoning were concealed under poisoning. Acute gastroenteritis with some dehydration $(n=1)$ was seen under GIT diseases.

\begin{tabular}{|l|c|c|}
\hline \multicolumn{3}{|l|}{ Table-1: Demographic details } \\
\hline Age (years) & Number (n) & Frequency (\%) \\
\hline Toddlers (1-3) & 14 & 45.16 \\
\hline Pre-school children (3-6) & 10 & 32.26 \\
\hline School going children (6-12) & 7 & 22.58 \\
\hline Sex & Number (n) & Frequency (\%) \\
\hline Male & 17 & 54.84 \\
\hline Female & 14 & 32.26 \\
\hline Total & 31 & 100 \\
\hline
\end{tabular}

\section{Discussion}

Ventilator associated pneumonia, multiple organ failure, septic shock, cardiovascular insufficiency and gastrointestinal bleeding occurs frequently following MV. The frequency of these complications is lower among children under low volume and pressure settings ${ }^{(6)}$. Increased in severity of the underlying diseases requiring MV is associated with higher rate of these complications. Paediatric MV is a sophisticated skill. Gaps in the knowledge among the doctors and trainees could be identified using MV testing 
tool. Thus, the paediatric critical care experts focus on the area to be taught to the trainees ${ }^{(7)}$. Sedation during MV compared with usual care has no difference in the duration of MV. However bizarre relation exists between agitation, wake fullness and pain among children ${ }^{(8)}$. Open suction of endotracheal tube is done to prevent fluid accumulation in the tube causing block in the circuit. Closed suction by multiple ports has shown no significant changes in the outcome when compared to open circuit suctioning. However, the MV can continue during the suctioning process when done by the latter one ${ }^{(9)}$. High frequency oscillatory ventilation and conventional ventilation is associated with poor outcomes ${ }^{(10-12)}$.

\section{Conclusion}

The point prevalence of ventilator associated pneumoniawas 19.35 seen in bronchiolitis $(n=4)$ and refractory seizure $(n=2)$. Relatively poor outcome is seen among children on MV when done for apnoea and hypoxemia.

\begin{tabular}{|c|c|c|c|c|c|c|}
\hline S. No. & Disease & \multirow{2}{*}{\multicolumn{2}{|c|}{ Number (\%) }} & Outcome & \multicolumn{2}{|c|}{ Number $(\%)$} \\
\hline \multirow{2}{*}{1} & \multirow{2}{*}{ Central nervous system diseases } & & \multirow{2}{*}{29.03} & Relieved & 8 & 25.81 \\
\hline & & 9 & & Expired & 1 & 3.23 \\
\hline \multirow[b]{2}{*}{2} & \multirow{2}{*}{ Respiratory diseases } & \multirow{2}{*}{8} & \multirow[t]{2}{*}{25.81} & Relieved & 6 & 19.35 \\
\hline & & & & Expired & 2 & 6.45 \\
\hline \multirow{2}{*}{3} & \multirow{2}{*}{ Cardiovascular system diseases } & \multirow{2}{*}{2} & \multirow{2}{*}{6.45} & Relieved & 1 & 3.23 \\
\hline & & & & Expired & 1 & 3.23 \\
\hline \multirow{2}{*}{4} & \multirow{2}{*}{ Dyselectrolytemia following drowning } & \multirow{2}{*}{3} & \multirow{2}{*}{9.68} & Relieved & 1 & 3.23 \\
\hline & & & & Expired & 2 & 6.45 \\
\hline \multirow{2}{*}{5} & \multirow{2}{*}{ Poisoning } & \multirow{2}{*}{8} & \multirow[t]{2}{*}{25.81} & Relieved & 7 & 22.58 \\
\hline & & & & Expired & 1 & 3.23 \\
\hline \multirow{2}{*}{6} & \multirow{2}{*}{ Gastrointestinal system diseases } & \multirow{2}{*}{1} & \multirow{2}{*}{3.23} & Relieved & 1 & 3.23 \\
\hline & & & & Expired & 0 & 0.00 \\
\hline \multirow{2}{*}{ Total } & & \multirow{2}{*}{31} & \multirow{2}{*}{100} & Relieved & 24 & 77.42 \\
\hline & & & & Expired & 7 & 22.58 \\
\hline
\end{tabular}

\begin{tabular}{|c|c|c|c|c|c|c|}
\hline S. No. & Indication & \multicolumn{2}{|c|}{ Number $(\%)$} & Outcome & \multicolumn{2}{|c|}{ Number (\%) } \\
\hline \multirow{2}{*}{1} & \multirow{2}{*}{ Cyanosis } & \multirow{2}{*}{3} & \multirow[t]{2}{*}{9.68} & Relieved & 2 & 6.45 \\
\hline & & & & Expired & 1 & 3.23 \\
\hline \multirow{2}{*}{2} & \multirow[b]{2}{*}{ Chest retractions } & \multirow{2}{*}{7} & \multirow[t]{2}{*}{22.58} & Relieved & 6 & 19.35 \\
\hline & & & & Expired & 1 & 3.23 \\
\hline \multirow[b]{2}{*}{3} & \multirow[b]{2}{*}{ Apnoea } & \multirow{2}{*}{12} & \multirow{2}{*}{38.71} & Relieved & 9 & 29.03 \\
\hline & & & & Expired & 3 & 9.68 \\
\hline \multirow{2}{*}{4} & \multirow{2}{*}{ Hypoxia } & \multirow{2}{*}{9} & \multirow{2}{*}{29.03} & Relieved & 7 & 22.58 \\
\hline & & & & Expired & 2 & 6.45 \\
\hline \multirow{2}{*}{ Total } & & \multirow{2}{*}{31} & \multirow{2}{*}{100} & Relieved & 24 & 77.42 \\
\hline & & & & Expired & 7 & 22.58 \\
\hline
\end{tabular}

\section{References}

1. Goto T, Gibo K, Hagiwara Y, Okubo M, Brown D, Brown C, et al. Factors Associated with First-Pass Success in Pediatric Intubation in the Emergency Department. West J Emerg Med. 2016;17(2):129-34.
2. Drašković B, Rakić G. Complications of mechanical ventilation. Srp Arh Celok Lek. 2011;139(9-10):685-92.

3. Amanati A, Karimi A, Fahimzad A, Shamshiri AR, Fallah F, Mahdavi A, et al. Incidence of Ventilator-Associated Pneumonia in Critically Ill Children Undergoing Mechanical Ventilation in 
Pediatric Intensive Care Unit. Children. 2017;4(7):56.

4. Aspesberro F, Guthrie KA, Woolfrey AE, Brogan T V., Roberts JS. Outcome of pediatric hematopoietic stem cell transplant recipients requiring mechanical ventilation. J Intensive Care Med. 2014;29(1):31-7.

5. Cheifetz IM. Invasive and noninvasive pediatric mechanical ventilation. Respir Care. 2003;48(4):442-8.

6. Rsovac S, Milosevic K, Nestorovic B, Nikolic A. Complications of mechanical ventilation in pediatric patients in Serbia. Adv Clin Exp Med. 2014; 23(1):57-61.

7. O'Boyle AL, Mink RB, Anas NG, Kallay TC. Development of learning objectives and a validated testing tool for management of pediatric mechanical ventilation. Pediatr Crit Care Med. 2014;15(7):594-9.

8. Civelek M, Lusis AJ, Genetics M, Angeles L. HHS Public Access. 2014;15(1):34-48.

9. Morrow BM, Mowzer R, Pitcher R, Argent AC. Investigation into the effect of closed-system suctioning on the frequency of pediatric ventilator-associated pneumonia in a developing country. Pediatr Crit Care Med. 2012;13(1):25-32.

10. Conti G, Piastra M. Mechanical ventilation for children. Curr Opin Crit Care. 2016;22(1):60-6.

11. Gupta P, Green JW, Tang X, Gall CM, Gossett JM, Rice TB, et al. Comparison of high-frequency oscillatory ventilation and conventional mechanical ventilation in pediatric respiratory failure. JAMA Pediatr. 2014;168(3):243-9.

12. Ingelse SA, Wiegers HMG, Calis JC, Van Woensel JB, Bem RA. Early Fluid Overload Prolongs Mechanical Ventilation in Children with Viral-Lower Respiratory Tract Disease*. Pediatr Crit Care Med. 2017; 18(3):e106-11. 